\title{
A NEW MANY-PURPOSE CULTURE MEDIUM FOR CHEMOTHERAPEUTIC AND MICROBIOLOGIC STUDIES
}

\author{
Joseph V. Uri and PAUL Actor \\ Research and Development Division, Smith Kline \& French!Laboratories \\ Philadelphia, Pennsylvania 19101, U.S.A. \\ (Received for publication January 21, 1980)
}

\begin{abstract}
A new semisynthetic culture medium was prepared and found to serve many useful purposes in chemotherapeutical research and also in diagnostic microbiology. It contains $0.5 \%$ peptone, $0.1 \%$ glucose and is supplemented with $10 \%$ McIlvaINE's buffer. The medium is $\mathrm{pH}$-stable and, being almost colorless, it is suitable for turbidimetric studies and enzymatic experiments which involve color-changes. For in vitro chemotherapeutic experimental studies it is a useful medium and, in certain cases, it behaves like an almost antagonist-free medium. Used as broth or in agar-base, it supports the growth of all of the 280 clinically important strains studied, including aerobic bacteria, Candida and Trichophyton. It promotes the germ tube formation of $C$. albicans and $C$. stellatoidea.
\end{abstract}

The culture media used in aerobic bacteriology and mycology are generally categorized into three major groups: 1. completely synthetic, 2 . semisynthetic, and 3. complex organic media. Media within the last two groups may be good supporters of the growth of almost all aerobic microbes. Synthetic media composed of an inorganic nitrogen source, salts and glucose cannot be used universally because several bacterial genera including staphylococci do not grow in or on them. On the other hand, the composition of the complex organic media is not readily reproducible; they are usually colored and not regularly buffered. We were looking for a colorless and $\mathrm{pH}$-stable medium which supports the growth of at least nonfastidious bacteria and fungi. The description of such a medium with a relatively simple composition and easy preparation and its use in studies on antibacterial agents, in microbial biochemistry and in diagnostic microbiology is the subject of this paper.

\section{Materials and Methods}

\section{Chemicals and Antibiotics}

The chemicals used (glucose, citric acid, dibasic sodium phosphate and bacto-peptone-Difco) were commercial preparations and, whenever applicable, of analytical grade. Nitrocefin (Glaxo chromogenic cephalosporin compound 87/312), primycin (Medimpex), clavulanic acid (Beecham), cefoxitin and cefmetazole (CS-1170) (Merck Sharp \& Dohme), cefotaxime (Hoechst-Roussel), alaphosphin (Roche) were kindly provided as research samples; SK\&F 73678 (a cephamycin) was synthesized at Smith Kline and French Laboratories.

Microbial Strains

All the microbial strains used throughout these studies were from the culture collection of Smith Kline and French Laboratories. They are maintained on appropriate microbiologic media under standard conditions.

Growth Support Studies

Our attempt to find a medium with the characteristics outlined in the introduction started with a $0.5 \%$ peptone water medium. ${ }^{10)}$ Since it did not support the growth of several microbes adequately, it was enriched with various amounts $(0.1,0.25,0.5$ and $1.0 \%)$ of glucose (dextrose). In all cases, 
the $\mathrm{pH}$ was adjusted to 7.3 and the buffer capacity was reinforced by the addition of $10 \%$ McIlvaine's citric acid-phosphate buffer ( $\mathrm{pH}$ 7.3). ${ }^{7}$ In these five media, the optical density of nine microbial strains, regularly used in our screen to determine antimicrobial activity, was measured after overnight growth $\left(37^{\circ} \mathrm{C}\right)$. In addition, the growth of three Staphylococcus aureus, three Escherichia coli and one Enterobacter cloacae strain all well-characterized previously ${ }^{14)}$, was monitored turbidimetrically ${ }^{3)}$ using a Bausch \& Lomb spectrophotometer (Spectronic 70) at $500 \mathrm{~nm}$. The final pH values of the cultures were measured (Fisher Accument Model 220 pH Meter). The growth supporting capacity of the medium found to be optimal in the above studies was then examined using an additional 280 mainly bacterial strains.

Composition and Preparation of the Medium

The addition of $0.1 \%$ glucose was found to support growth adequately and not to change the $\mathrm{pH}$. Thus, the medium used in our subsequent study consisted of $0.5 \%$ peptone, $0.1 \%$ glucose (dextrose) and 10\% McIlvaINE's citric acid-phosphate buffer ( $\mathrm{pH} 7.3$ ), ${ }^{7)}$ and is referred to as PGB (peptone-glucose-buffered) medium. The ingredients were prepared and autoclaved separately and combined aseptically. The glucose was autoclaved as a $40 \%$ stock solution with the addition of two drops phosphoric acid to prevent caramelization. The medium can be solidified by addition of $1.7 \%$ agar to the peptone water and when cooled to $50^{\circ} \mathrm{C}$, supplemented with the calculated volumes of the glucose and buffer solutions.

Studies Using the PGB Medium

For MIC determinations using the serial tube dilution method, $3 \mathrm{ml}$ of the liquid medium was employed regularly. This volume permits monitoring of growth with the naked eye and turbidimetrically. The test compound and the inoculum (overnight grown culture in the same medium) were added in $0.05 \mathrm{ml}$ volumes and the tubes were incubated at $37^{\circ} \mathrm{C}$ in the case of bacteria and $30^{\circ} \mathrm{C}$ in the case of Candida spp. and dermatophytes.

The bacterial growth-kinetics and responses to antibacterial agents were studied in PGB medium in stationary cultures $\left(37^{\circ} \mathrm{C}\right)$ by recording changes in turbidity. Such a system allows measurement of drug induced or spontaneous bacteriolysis. Antibacterial agents were added to exponential phase cultures with an optical density (O.D.; absorbance) of about 0.4. Readings were taken at the start, then hourly for 8 hours and at 24 hours. The dynamics of the lytic potential of several $\beta$-lactam antibiotics and other cell-wall active agents have been studied in this medium. ${ }^{14}$ )

The PGB medium was evaluated for the detection of $\beta$-lactamase activity by following color production with nitrocefin ${ }^{9)}$. This system allowed demonstration of the presence of $\beta$-lactamase inhibitors ${ }^{13)}$. The inhibitor and nitrocefin were added in $0.05 \mathrm{ml}$ volume each to $0.5 \mathrm{ml}$ of PGB medium in which the bacteria were grown or suspended. The change from colorless to pink or purple could be read visually and spectrophotometrically.

Germ tube formation of Candida strains was studied in $2 \mathrm{ml}$ of the PGB medium inoculated with $0.1 \mathrm{ml}$ of an overnight culture $\left(30^{\circ} \mathrm{C}\right)$ of C. albicans $\$ 759$ or C. stellatoidea $\$ 2245$ in the same medium. After two hours at $37^{\circ} \mathrm{C}$, the germ tube formation was observed by light or phase-contrast microscopy.

\section{Results}

The results obtained by adding glucose to the buffered peptone water are presented in Table 1 . With few exceptions (Providencia sp., Enterobacter cloacae and Serratia marcescens), the bacterial strains and C. albicans grew better on the glucose enriched medium. Most strains grew well at any of the glucose concentrations. At $0.1 \%$ glucose, the $\mathrm{pH}$ of the overnight cultures remained fairly constant (7.0 7.3). At higher glucose concentrations $(0.25 \sim 1.0 \%)$, the medium tended to become acidic, which is undesirable for many experiments.

The growth of selected seven strains in Table 1 was followed kinetically. Again, the data clearly demonstrated that the addition of $0.1 \%$ glucose was optimal, both for growth promotion and for 
Table 1. The influence of glucose concentrations on the growth and $\mathrm{pH}$ of selected microorganisms in peptone water. Incubation for 24 hours at $37^{\circ} \mathrm{C}$.

\begin{tabular}{|c|c|c|c|c|c|}
\hline \multirow{2}{*}{ Strains } & \multicolumn{5}{|c|}{ Optical density (absorbance) in medium } \\
\hline & $\begin{array}{l}\text { Peptone- } \\
\text { water }\end{array}$ & $\begin{array}{c}\text { Peptone }+ \\
0.1 \% \text { glucose }\end{array}$ & $\begin{array}{c}\text { Peptone }+ \\
0.25 \% \text { glucose }\end{array}$ & $\begin{array}{c}\text { Peptone }+ \\
0.5 \% \text { glucose }\end{array}$ & $\begin{array}{l}\text { Peptone }+ \\
1.0 \% \text { glucose }\end{array}$ \\
\hline Staph. aureus ATCC 25923 & 0.56 & 1.2 & 1.1 & 1.1 & 1.1 \\
\hline Staph. aureus $\$ 910$ & 0.40 & 1.3 & 1.2 & 1.3 & 1.2 \\
\hline Staph. aureus $\# 127$ & 0.68 & 1.4 & 1.3 & 1.3 & 1.3 \\
\hline Staph. aureus $\# 671$ & 0.69 & 1.3 & 1.2 & 1.3 & 1.3 \\
\hline Strep. faecalis $\# 34358$ & 0.29 & 0.94 & 0.66 & 0.55 & 0.86 \\
\hline E. coli $\# 12140$ & 0.75 & 1.6 & 1.6 & 1.3 & 1.2 \\
\hline E. coli $¥ 804$ & 0.82 & 1.3 & 1.2 & 1.2 & 1.4 \\
\hline E. coli $\# 211$ & 0.84 & 1.3 & 1.1 & 1.1 & 1.3 \\
\hline Kleb. pneumoniae $\# 4200$ & 0.57 & 0.70 & 0.75 & 0.96 & 0.96 \\
\hline Enter. cloacae $\# 31254$ & 1.1 & 1.3 & 1.3 & 1.1 & 1.1 \\
\hline Proteus mirabilis \#444 & 0.57 & 1.1 & 1.1 & 1.1 & 1.2 \\
\hline Proteus morganii $\# 179$ & 0.33 & 0.78 & 0.90 & 0.86 & 0.86 \\
\hline Providencia sp. $\$ 276$ & 1.0 & 1.0 & 1.0 & 0.96 & 0.98 \\
\hline Salmonella gallinarum $\# 595$ & 0.28 & 0.86 & 0.94 & 0.93 & 1.0 \\
\hline Serratia marcescens $\# 13880$ & 1.0 & 1.1 & 1.1 & 1.1 & 1.1 \\
\hline C. albicans $¥ 759^{*}$ & 0.44 & 0.88 & 1.4 & 1.4 & 1.4 \\
\hline Final $\mathrm{pH}$ & 7.3 & $7.3 \sim 7.0$ & $7 \sim 5.5$ & $6.5 \sim 5.5$ & $5.5 \sim 4.5$ \\
\hline
\end{tabular}

* Incubated at $30^{\circ} \mathrm{C}$.

Table 2. Microbial strains examined for growth in the peptone-glucose-buffered broth and agar.

\begin{tabular}{|c|c|c|c|}
\hline Microbes & $\begin{array}{l}\text { Number of } \\
\text { strains studied }\end{array}$ & Microbes & $\begin{array}{l}\text { Number of } \\
\text { strains studied }\end{array}$ \\
\hline Staphylococcus aureus and epidermidis & 31 & Salmonella paratyphi and gallinarum & 2 \\
\hline Streptococcus faecalis & 15 & Serratia marcescens & 26 \\
\hline Sarcina lutea & 1 & Pseudomonas aeruginosa & 10 \\
\hline Bacillus subtilis ATCC 6633 & 1 & Mycobacterium phlei & 1 \\
\hline Escherichia coli & 37 & Candida albicans & 10 \\
\hline Klebsiella pneumoniae & 34 & Candida spp. (other than albicans) & 5 \\
\hline Enterobacter cloacae and aerogenes & 27 & Trichophyton mentagrophytes & 4 \\
\hline Proteus mirabilis & 25 & Microsporum versicolor & 1 \\
\hline Proteus, indole-producing & 25 & & \\
\hline $\begin{array}{l}\text { Citrobacter, Providencia, Arizona, } \\
\text { Acinetobacter }\end{array}$ & 25 & Total & 280 \\
\hline
\end{tabular}

stabilization of the $\mathrm{pH}$.

The growth supporting quality of PGB medium using 280 microbial (bacterial and fungal) strains is summarized in Table 2. All strains grew well in or on this medium at $37^{\circ}$ or $30^{\circ} \mathrm{C}$ overnight (longer in the case of some fungi). Since the medium is colorless, it is also convenient for the study of the mechanisms of pigment formation of Pseudomonas aeruginosa, Serratia marcescens and Trichophyton strains.

The PGB broth was found to be convenient for MIC determination of various antimicrobial agents. The results of a typical in vitro assay are presented in Table 3, although many experiments were per- 
Table 3. Representative MIC values of cefotaxime and turbidimetric results in peptone-glucosebuffered (PGB) broth.

\begin{tabular}{|c|c|c|c|}
\hline \multirow{2}{*}{ Strains } & \multirow{2}{*}{$\begin{array}{c}\text { Minimal } \\
\text { inhibitory } \\
\text { concentration } \\
\mu \mathrm{g} / \mathrm{ml}\end{array}$} & \multicolumn{2}{|c|}{ Optical density } \\
\hline & & $\begin{array}{l}\text { at } \\
\text { MIC }\end{array}$ & Control \\
\hline $\begin{array}{c}\text { Staphylococcus } \\
\text { aureus } \# 674\end{array}$ & 1.5 & 0.10 & 1.15 \\
\hline $\begin{array}{c}\text { Staphylococcus } \\
\text { aureus } \sharp 671^{*}\end{array}$ & 1.5 & 0.11 & 1.3 \\
\hline $\begin{array}{l}\text { Escherichia coli } \\
\quad \# 12140\end{array}$ & $0.1 \sim 0.05$ & 0.12 & 1.4 \\
\hline $\begin{array}{l}\text { Escherichia coli } \\
\# 804^{*}\end{array}$ & 0.1 & 0.61 & 1.6 \\
\hline
\end{tabular}

* Strong $\beta$-lactamase producing strains.

formed. The MIC's for cefotaxime (HR-756) are in agreement with those obtained in conventional media ${ }^{2,5)}$. An added advantage of PGB medium is that the MIC can be measured turbidimetrically, not only visually (Table 3 ).

PGB medium is particularly useful for the study of growth kinetics and the influence of antibiotics on growth. The bacteriolytic-effect of cephamycins (cefoxitin, CS-1170 and SK\&F 73678) on various bacterial strains in this medium has been published ${ }^{14)}$. Additional studies include other cephamycins, ampicillin, and cephalosporins (to be published). Although PGB medium was rich enough to support the growth of all bacteria and fungi studied, in certain experiments it behaved like an "antagonistfree" medium. In turbidimetric experiments using a supplemented defined antagonist-free medium ${ }^{11}$ alaphosphin was shown to produce a rapid fall of optical density with complete lysis of the cells. A similar effect was found with Escherichia coli strains grown in PGB medium (Fig. 1). In the defined medium, the $E$. coli cells start to lyse at the time of addition of 1.5 or $3.0 \mu \mathrm{g} / \mathrm{ml}$ of alaphosphin, whereas in PGB broth there is some further growth before the lysis begins. Complete lysis occurs in both media after $4 \sim 5$ hours of incubation. Lysis is not observed in complex organic media because of the presence of antagonistic factor(s) that counteract the antibacterial effect of alaphosphin.

Candida albicans $\$ 759$ forms germ tubes in great frequency in PGB broth ${ }^{15)}$ as it does in human serum $^{12)}$ or in peptone water ${ }^{(\mathrm{)})}$. C. stellatoidea was also found to produce germ tubes but other Candida spp. did not. PGB medium may be useful for the differentiation of C. albicans and C. stellatoidea ${ }^{10)}$, and for the study of the mechanism of germ tube or bud formation ${ }^{4,8)}$. The concentration-dependent inhibition of germ tube formation of C. albicans $\$ 759$ by primycin correlated well with its static and candicidal activity in this medium. ${ }^{15}$

\section{Discussion}

The results obtained with the new PGB medium demonstrate its versatility in the microbiology laboratory. It is not only useful for the diagnostic propagation of various aerobic bacteria and fungi but because it is colorless and maintains $\mathrm{pH}$ during growth, it has wide applicability in various microbial biochemical and chemotherapeutic studies.

The PGB colorless medium can be advantageously used for the study of microbial enzymatic 
reactions which are accompanied by color change. It served as a basis for the development of a rapid and simple method for the detection of $\beta$-lactamase(s) inhibitors. The results obtained with clavulanic acid using $14 \beta$-lactamase producing bacterial strains have recently been published ${ }^{13)}$.

Its behavior in experiments as an antagonist-free medium with alaphosphin may extend to the study of other agents such as sulfonamides, D-cycloserine, bacilysin, vancomycin, fosfomycin, and the like, the action of which is known to be influenced by medium ingredients. The germ tube formation of $C$. albicans for diagnostic and research purposes can easily be studied in this simple, colorless, $\mathrm{pH}$-balanced and easily preparable medium, replacing serum, albumin and complex amino-acid containing media.

\section{Acknowledgements}

We gratefully acknowledge the skillful technical assistance of MARIE KNIGHT.

\section{References}

1) Allen, J. G.; F. R. Atherton, M. J. Hall, C. H. Hassall, S. W. Holmes, R. W. Lambert, L. J. Nisbet \& P.S. Ringrose: Phosphonopeptides as antibacterial agents: Alaphosphin and related phosphonopeptides. Antimicr. Agents \& Chemoth. 15: 684 695, 1979

2) Chabbert, Y. A. \& A. Lutz: HR-756, the $s y n$ isomer of a new methoxyimino cephalosporin with unusual antibacterial activity. Antimicr. Agents \& Chemoth. 14: 749 754, 1978

3) Greenwood, D.: In defense of turbidimetry. J. Antimicr. Chemoth. 3: 286 287, 1977

4) HAZEN, K. C. \& J. E. Cutler: Autoregulation of germ tube formation by Candida albicans. Infect. Inmun. 24: $661 \sim 666,1979$

5) Heymes, R.; A. Lutz \& E. Schrinner: Experimental evaluation of HR-756, a new cephalosporin derivative: pre-clinical study. Infection 5: 259 260, 1977

6) Joshi, K. R.; J. B. GAvin \& D. A. Bremner: The formation of germ tubes by Candida albicans in various peptone media. Sabouraudia 11:259 262, 1973

7) Mcllvaine, T. C.: A buffer solution for colorimetric comparison. J. Biol. Chem. 49: 183 186, 1921

8) Mitchell, L. H. \& D. R. Soll: Commitment to germ tube or bud formation during release from stationary phase in Candida albicans. Exp. Cell Res. 120: 167 179, 1979

9) O’Callaghan, C. H.; A. Morris, S. Kirby \& A. H. Shingler: Novel method for detection of $\beta$-lactamases by using a chromogenic cephalosporin substrate. Antimicr. Agents \& Chemoth. 1: 283 288, 1972

10) Salkin, I. F.: New medium for differentiation of Candida albicans from Candida stellatoidea. J. Clin. Microbiol. 9: 551 553, 1979

11) Selwyn, S.: Rational choice of penicillins and cephalosporins based on parallel in vitro and in vivo tests. Lancet 1976-2: 616 618, 1976

12) Silva-Hunter, M. \& B. H. Cooper: Medically important yeasts. in E. H. Lennette, E. H. Spaulding \& J. P. Truant (ed), Manual of Clinical Microbiology, pp. 496 498, American Society for Microbiology, Washington, DC, 1974

13) URI, J. V.; P. Actor \& J. A. WeisBaCH: Rapid and simple method for detection of $\beta$-lactamase inhibitors. J. Antibiotics 31: 789 791, 1978

14) Uri, J. V.; P. Actor, J. R. Guarini, L. Phillips, D. Pitkin, R. M. DeMarinis \& J. A. Weisbach: Biologi$\mathrm{cal}$ and chemotherapeutic studies on three semisynthetic cephamycins. J. Antibiotics 31: 82 91, 1978

15) URI, J. V.\& P. ACTOR: Crystallization and antifungal activity of primycin. J. Antibiotics 32: 1207 1209, 1979 